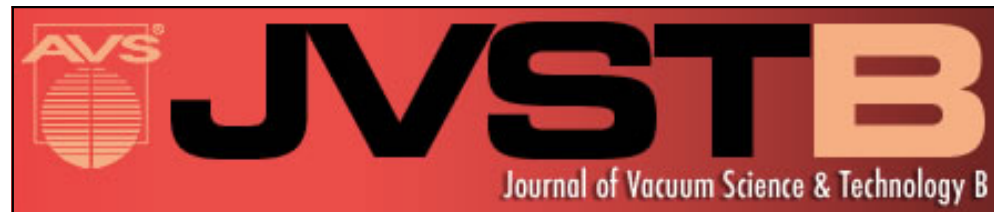

\title{
Schottky-diode hydrogen sensor based on InGaN/GaN multiple quantum wells
}

Gang Chen, Anthony Hoi Wai Choi, Pui To Lai, and Wing Man Tang

Citation: Journal of Vacuum Science \& Technology B 32, 011212 (2014); doi: 10.1116/1.4855057

View online: http://dx.doi.org/10.1116/1.4855057

View Table of Contents: http://scitation.aip.org/content/avs/journal/jvstb/32/1?ver=pdfcov

Published by the AVS: Science \& Technology of Materials, Interfaces, and Processing

\section{Articles you may be interested in}

High efficiency InGaN/GaN light emitting diodes with asymmetric triangular multiple quantum wells

Appl. Phys. Lett. 104, 091111 (2014); 10.1063/1.4867023

An optically detectable $\mathrm{CO} 2$ sensor utilizing polyethylenimine and starch functionalized InGaN/GaN multiple quantum wells

Appl. Phys. Lett. 103, 022109 (2013); 10.1063/1.4813604

Effect of humidity on hydrogen sensitivity of Pt-gated AIGaN/GaN high electron mobility transistor based sensors Appl. Phys. Lett. 96, 232106 (2010); 10.1063/1.3454279

Mapping of multiple-quantum-well layers and structure of $\mathrm{V}$ defects in InGaN/GaN diodes Appl. Phys. Lett. 84, 2271 (2004); 10.1063/1.1689740

Influence of surface oxides on hydrogen-sensitive Pd:GaN Schottky diodes

Appl. Phys. Lett. 83, 773 (2003); 10.1063/1.1593794

\section{AVS 61 ${ }^{\text {ST }}$ INTERNATIONAL SYMPOSIUM \& EXHIBITION}

\section{November 9-14, 2014 Baltimore, Maryland}
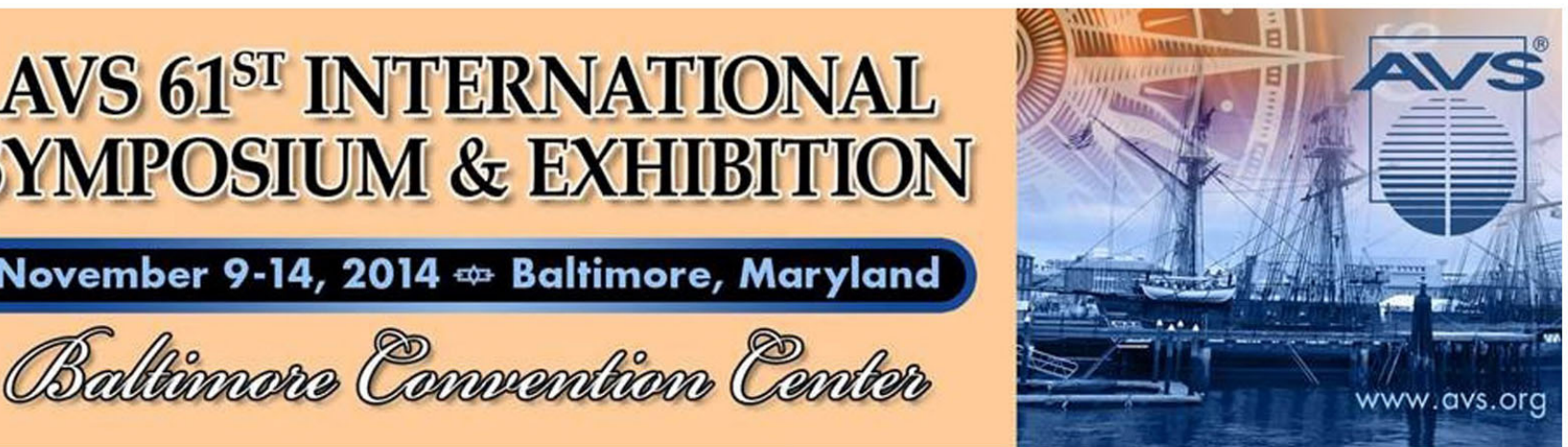


\title{
Schottky-diode hydrogen sensor based on InGaN/GaN multiple quantum wells
}

\author{
Gang Chen, Anthony Hoi Wai Choi, and Pui To Lai ${ }^{a}$ \\ Department of Electrical and Electronic Engineering, The University of Hong Kong, Pokfulam Road, \\ Hong Kong \\ Wing Man Tang \\ Department of Applied Physics, The Hong Kong Polytechnic University, Hung Hom, Hong Kong
}

(Received 14 August 2013; accepted 5 December 2013; published 8 January 2014)

\begin{abstract}
A Schottky-diode hydrogen sensor based on InGaN/GaN multiple quantum wells was fabricated. Its hydrogen-sensing properties (e.g., current-voltage characteristics, barrier-height variation, and response) and its hydrogen adsorption properties (e.g., hydrogen reaction kinetics, transient behavior, response time, and activation energy) were studied over a wide range of temperature or $\mathrm{H}_{2}$ concentration. Results showed that the device is sensitive to hydrogen ambient even at high temperature (response is 0.11 at $300^{\circ} \mathrm{C}$ in $810 \mathrm{ppm} \mathrm{H}_{2}$ ). According to the kinetic adsorption analysis, the activation energy of the sensor is $4.9 \mathrm{kcal} / \mathrm{mol}$. Moreover, the sensor could perform rapid hydrogen detection at high temperature (response time is $25.1 \mathrm{~s}$ at $400^{\circ} \mathrm{C}$ in $800 \mathrm{ppm} \mathrm{H}_{2}$ ). Therefore, the sensor is a useful device for hydrogen-sensing applications, especially at high temperature. (C) 2014 American Vacuum Society. [http://dx.doi.org/10.1116/1.4855057]
\end{abstract}

\section{INTRODUCTION}

In the current energy-driven economy, hydrogen has the potential to act as an alternative fuel source that is efficient and environmentally friendly. Hydrogen has been explored for conventional technologies such as hydrocracking of paraffin in petroleum refineries, fuel cells, internal combustion engines, power generation, etc. Hydrogen is known to have excellent combustible and explosive properties, but also has a high tendency to leak through containers or pipe lines due to its small molecular size. Thus, all hydrogen applications have safety issues requiring continuous and accurate monitoring for hydrogen leak during its transport, storage, and use. Therefore, reliable and efficient detection of $\mathrm{H}_{2}$ is very important to avoid any disaster associated with flammable and explosive $\mathrm{H}_{2} \cdot{ }^{1,2}$

During the past decades, different Schottky-diode metalsemiconductor (MS) structures were studied for the detection of hydrogen gas. ${ }^{3-5}$ These sensors are fabricated with semiconductor as sensing platform and catalytic metal as sensing metal. Several catalytic metals such as palladium (Pd), platinum $(\mathrm{Pt})$, and nickel $(\mathrm{Ni})$ can dissociate hydrogen molecules spontaneously. Then, hydrogen atoms diffuse to the $\mathrm{M} / \mathrm{S}$ interface and create a dipole layer, thus lowering the effective work function of the metal and changing the electrical characteristics of the devices. Regarding the sensing platform suitable for the hydrogen sensor, $\mathrm{Si}, \mathrm{SiC}$, and GaN-based semiconductors are usually considered. ${ }^{6,7}$ For instance, in Refs. $8-10, \mathrm{Pt} / \mathrm{GaN}$ or Pd/GaN Schottky diodes were prepared for hydrogen detection. After dissociated by the catalytic metal (Pt or Pd), atomic hydrogen accumulation at the $\mathrm{M} / \mathrm{S}$ (i.e., $\mathrm{Pt} / \mathrm{GaN}$ or $\mathrm{Pd} / \mathrm{GaN}$ ) interface changed the work function of the metal gate and hence the Schottky barrier height, resulting in a shift of the $I-V$ curve of the diode. Although many GaN-based hydrogen sensors were proposed

a)Electronic mail: laip@eee.hku.hk by others, no MS Schottky-diode sensor with a structure involving InGaN/GaN multiple quantum wells (MQWs) has been studied.

Major developments in III-nitride semiconductors have led to the commercial production of InGaN-based multiplequantum-well light-emitting diodes and laser diodes. ${ }^{11}$ In order to see whether InGaN/GaN MQW structure can be useful in the MS Schottky-diode hydrogen sensor for possible integration with optoelectronic devices, it will be fabricated and investigated in detail.

\section{EXPERIMENTAL DETAILS}

Hydrogen sensor with the Pt/MQW Schottky-diode structure shown in Fig. 1 was fabricated. The wafer was cleaned by the commonly used Radio Corporation of America method [solution I $\left(\mathrm{H}_{2} \mathrm{O}-\mathrm{H}_{2} \mathrm{O}_{2}-\mathrm{NH}_{4} \mathrm{OH}\right)$ and solution II $\left.\left(\mathrm{H}_{2} \mathrm{O}-\mathrm{H}_{2} \mathrm{O}_{2}-\mathrm{HCl}\right)\right]$ (Refs. 12 and 13) followed by a 1-min dipping in 5\% hydrofluoric acid, which was used to remove the native oxide, in a plastic beaker. Subsequently, the wafer was rinsed in deionized (DI) water and blown dry with nitrogen gas. An electrode, $100-\mathrm{nm}$ Pt with a diameter of $0.5 \mathrm{~mm}$, was then deposited on the wafer by DC sputtering (at $0.2 \mathrm{~A}$ ) of platinum metal in an Ar ambient through a stainless-steel shadow mask. Next, the wafer underwent an annealing in a furnace at $650^{\circ} \mathrm{C}$ in $\mathrm{N}_{2}(1000 \mathrm{ml} / \mathrm{min})$ for $10 \mathrm{~min}$ to stabilize the sensing performance at high operating temperatures. Then, 20\% hydrofluoric acid was used to remove the silicon dioxide at the back of the wafer grown during the annealing. Later, the wafer was rinsed again in DI water and blown dry with nitrogen gas. After that, the wafer was cut into dices and each dice was pasted on a header using silver epoxy. The header was then put into an oven at $200{ }^{\circ} \mathrm{C}$ for half an hour to harden the silver epoxy. Finally, a gold wire was connected between the front electrode of the sensor and one of the pins of the header using a hybrid wedge bonder. 
(a)

\begin{tabular}{|c|}
\hline $\operatorname{Pt}(100 \mathrm{~nm})$ \\
\hline undoped GaN cap $(20 \mathrm{~nm})$ \\
\hline InGaN/GaN MQWs $(60 \mathrm{~nm})$ \\
\hline $\mathrm{n}-\mathrm{GaN}(5 \mu \mathrm{m})$ \\
\hline Silicon \\
\hline
\end{tabular}

$-$

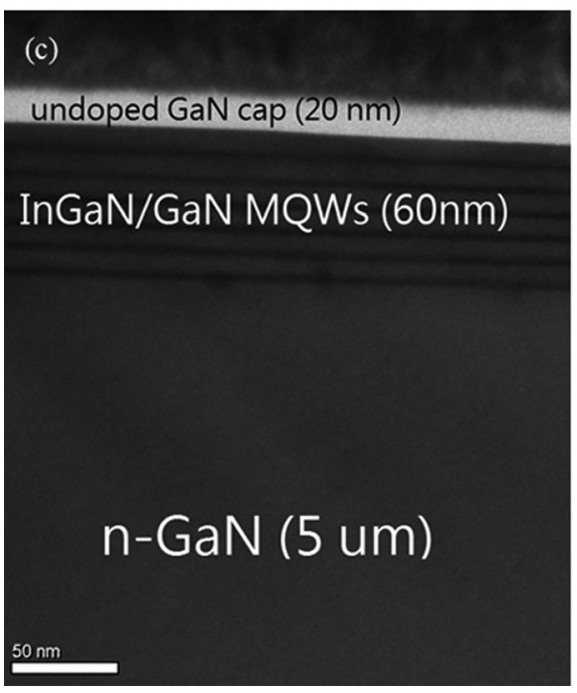

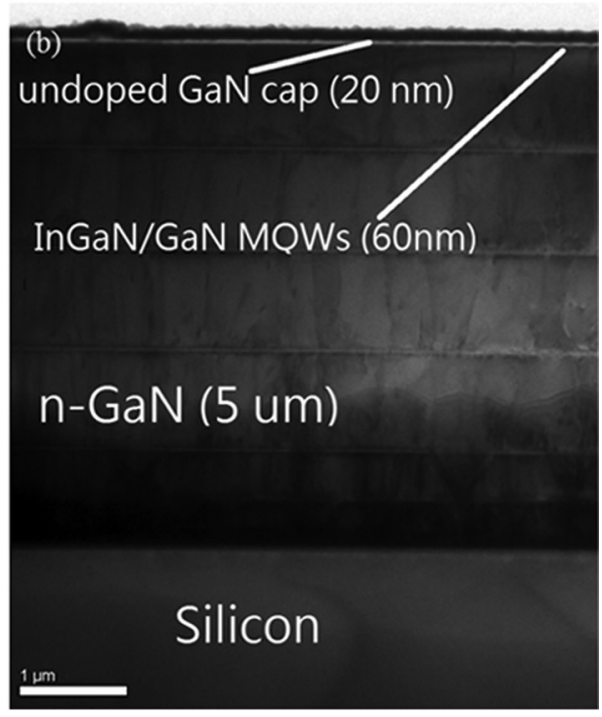

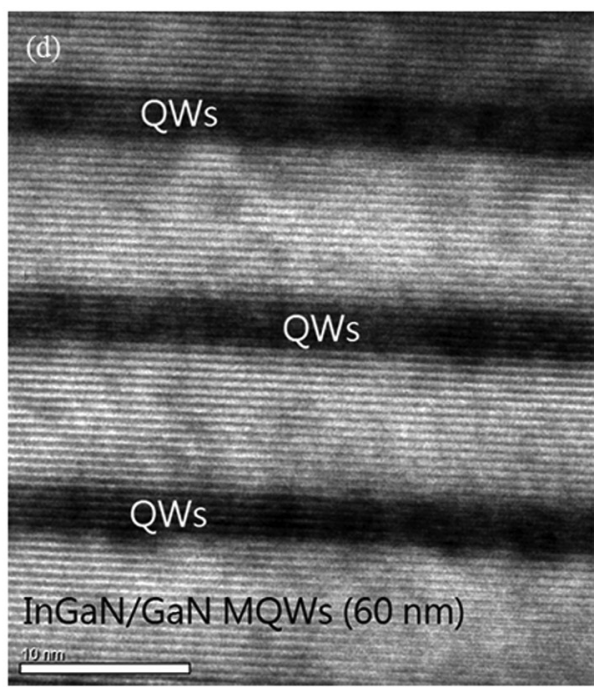

FIG. 1. (a) Schematic diagram of the hydrogen sensor. (b)-(d) TEM images of the device structure with different magnifications.

After fabrication of the hydrogen sensor, its hydrogensensing properties were studied. Measurements were carried out using a computer-controlled measurement system shown in Fig. 2. A thermostat, a semiconductor parameter analyzer (HP4145B), and two digital gas flow controllers (DGFCs) were connected to a computer and controlled by software programs. The sensor was placed in a stainlesssteel closed chamber inside the thermostat, and gases were injected into the chamber through the digital gas flow controllers to vary the hydrogen concentration. Two gas cylinders were used in the measurements. One was synthetic air, and the other was $0.1 \% \mathrm{H}_{2}$ in air. Each gas cylinder was connected to a DGFC. Different gas flow rates of the two DGFCs resulted in different hydrogen concentrations in air. Same as others, ${ }^{14-16}$ hydrogen relative response ratio $(R)$ was defined as $R=\left(I_{H 2}-I_{\text {air }}\right) / I_{\text {air }}$, where $I_{H 2}$ and $I_{\text {air }}$ were currents measured in hydrogen ambient and dry air, respectively.

\section{RESULTS AND DISCUSSION}

In order to study its $I-V$ characteristics, the sensor was tested from room temperature $\left(25^{\circ} \mathrm{C}\right)$ to $400^{\circ} \mathrm{C}$ and exposed to dry air or hydrogen ambient of three different concentrations $(429,619$, and $810 \mathrm{ppm})$. Typical $I-V$ curves of the sensor are shown in Fig. 3, and they exhibit good $I-V$ characteristics of a Schottky diode. Its hydrogen sensing mechanisms are briefly elaborated as follows. When hydrogen gas is introduced, some hydrogen molecules are dissociated at the catalytic Pt metal surface and become hydrogen atoms. These hydrogen atoms then diffuse through the thin Pt metal film until they adsorb at the Pt/GaN MS interface. The hydrogen atoms adsorbed at the MS interface become polarized and form a dipolar layer. This leads to a modulation of the effective barrier height at the MS interface, and thus a change of both forward- and reverse-biased currents. ${ }^{17}$ The mechanisms of the impact of the InGaN/GaN MQWs on the response can be simply explained as follows. In the 


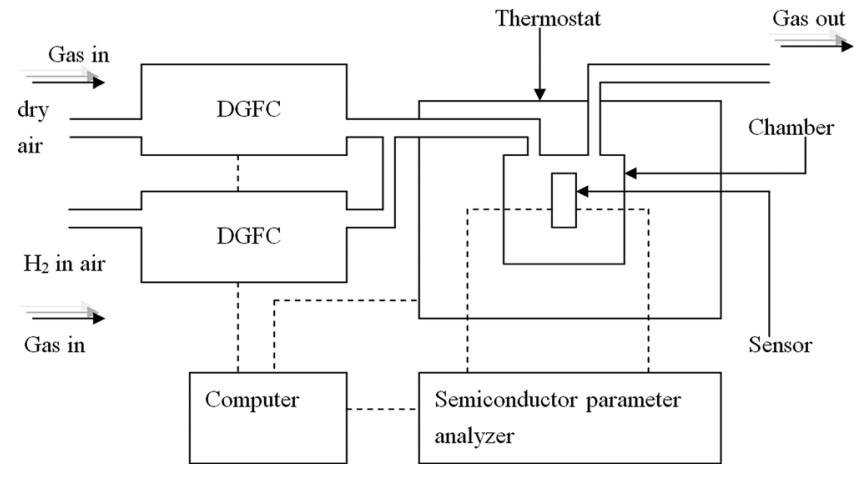

FIG. 2. Computer-controlled measurement system.

InGaN/GaN MQWs, the interfaces and nanoscale indium composition fluctuations (due to indium aggregation or phase separation) can hinder the flow of charge carriers, while the QWs can enhance the recombination between electrons and holes. ${ }^{18}$ As a result, the leakage current $\left(I_{\text {air }}\right)$ is reduced, but only slightly due to the very small overall thickness of the QWs (see Fig. 1). On the other hand, the change in current $\left(I_{H 2}-I_{\text {air }}\right)$ is dependent on the barrier-height variation $\left(\Delta \Phi_{b}\right)$, which only relies on the dipole layer formed by hydrogen atoms at the MS interface outside the MQWs. Therefore, the response, which is defined as $\left(I_{H_{2}}-I_{\text {air }}\right) / I_{\text {air }}$, can be increased when MQWs are involved in the substrate structure.

Figure 4 describes the response-temperature characteristics of the hydrogen sensor. As can be seen, the response reaches its maximum at $300^{\circ} \mathrm{C}$. This phenomenon can be explained as follows. ${ }^{19}$ When the temperature rises from 25 to $300{ }^{\circ} \mathrm{C}$, the kinetic energy of hydrogen molecules increases. So, there is an increase of $\mathrm{H}_{2}$ dissociation into $\mathrm{H}$ atoms, resulting in an increase of $\mathrm{H}$ accumulation at the $\mathrm{Pt} / \mathrm{GaN}$ interface, and hence leading to an increase of the response. Nevertheless, when the temperature further increases from 300 to $400^{\circ} \mathrm{C}$, the oxygen atoms in dry air attached to the surface of the electrode can react with the hydrogen atoms to form hydroxyl ions and water. ${ }^{20}$ The formation rates of these products increase rapidly at high temperature, thus decreasing the response.

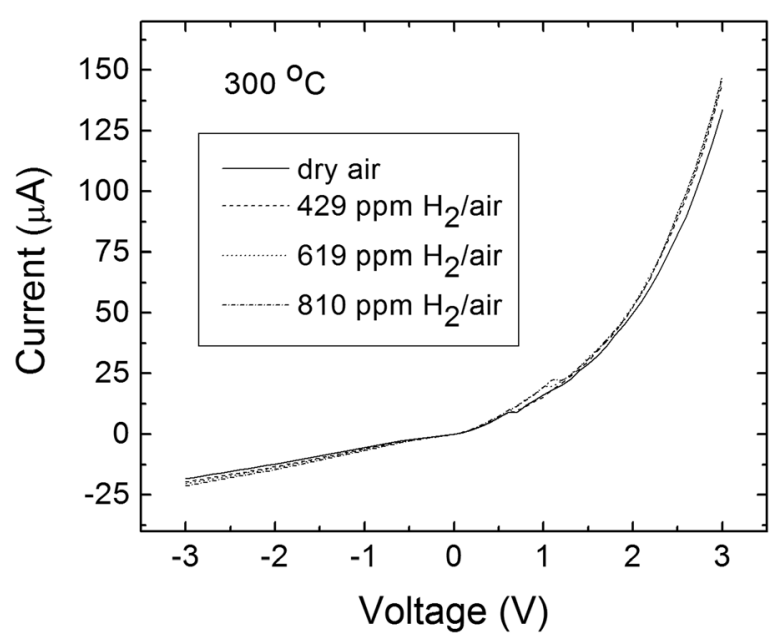

FIG. 3. Typical $I-V$ curves of the sensor at $300^{\circ} \mathrm{C}$.

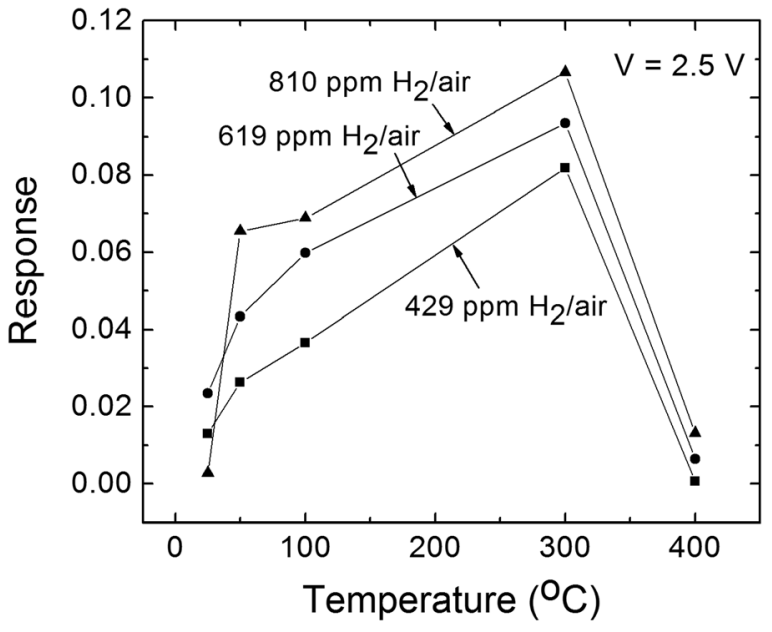

FIG. 4. Response vs temperature characteristics of the sensor.

Based on the thermionic-emission model, ${ }^{21}$ the Schottky barrier height $\left(\Phi_{b}\right)$ can be calculated as

$$
\Phi_{b}=\left(k_{B} T / q\right) \ln \left(A A^{* *} T^{2} / I_{o}\right),
$$

where $k_{B}$ is the Boltzmann constant, $T$ is the absolute temperature, $A$ is the Schottky contact area, $A^{* * *}$ is the effective Richardson constant, and $I_{o}$ is the saturation current. The barrier-height variation $\left(\Delta \Phi_{b}\right)$ is defined as $\Delta \Phi_{b}=\Phi_{b}$ (air) $-\Phi_{b}\left(\mathrm{H}_{2}\right)$, where $\Phi_{b}$ (air) is the barrier height in an air atmosphere; and $\Phi_{b}\left(\mathrm{H}_{2}\right)$ is the barrier height in a hydrogencontaining ambient. $I_{o}$ (in dry air or in $\mathrm{H}_{2}$ ) can be found from the corresponding $y$-intercept of the graph of $\ln (I)$ versus $V$, and then $\Phi_{b}$ can be calculated using the equation above. As a result, $\Delta \Phi_{b}$ is known, and both Figs. 5 and 7 can be plotted. In Fig. 5, the barrier-height variation goes down at high temperature. This phenomenon is elaborated in the following. The formation rates of hydroxyl ions and water increase rapidly at high temperature as more hydrogen atoms react with the oxygen atoms attached to the surface of the electrode, resulting in a decrease of hydrogen atoms accumulated at the $\mathrm{Pt} / \mathrm{GaN}$ interface. Hence, at higher temperature,

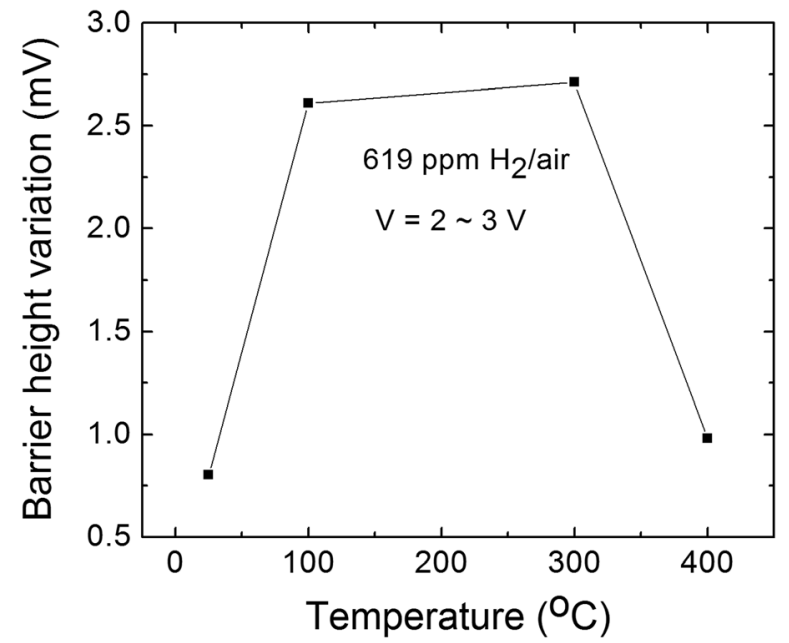

FIG. 5. Barrier-height variation vs temperature characteristics of the sensor. 


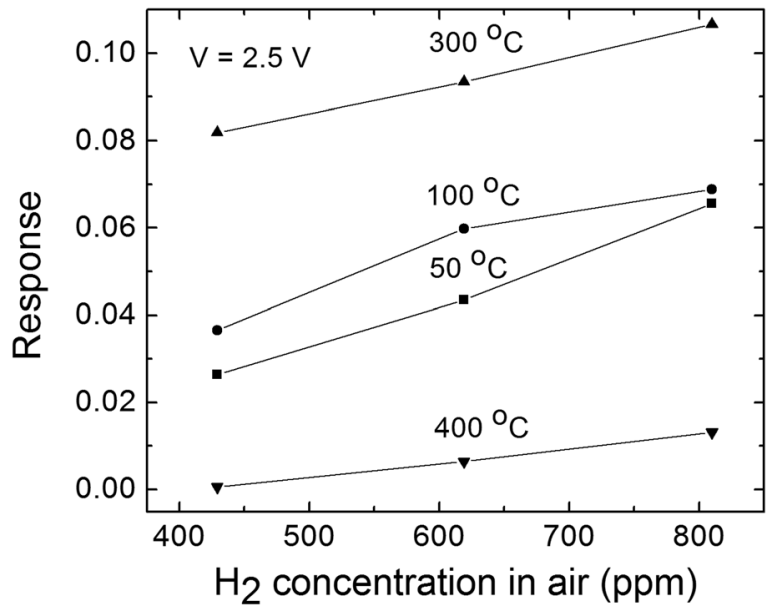

FIG. 6. Response vs $\mathrm{H}_{2}$ concentration characteristics of the sensor.

the dipolar layer formed by fewer accumulated $\mathrm{H}$ atoms builds a weaker local electric field and lowers the barrier height less, thus smaller the barrier-height variation.

It is shown in Fig. 6 that the response increases when the hydrogen concentration increases. This is due to an increase of $\mathrm{H}_{2}$ dissociation into $\mathrm{H}$ atoms at the surface of the catalytic metal $\mathrm{Pt}$, thus an increase of $\mathrm{H}$ accumulation at the $\mathrm{Pt} / \mathrm{GaN}$ interface, and therefore an increase of the response. Besides, Fig. 7 depicts that the barrier-height variation also increases with the $\mathrm{H}_{2}$ concentration. This is due to a current increase of the sensor in a hydrogen-containing ambient caused by the lowering of the Schottky barrier at the MS interface. The hydrogen atoms accumulated at the interface form a dipolar layer to build a local electric field and thus reduce the barrier height there.

Under steady-state condition, hydrogen coverage $(\theta)$ at the interface according to reaction kinetics can be represented as 22,23

$$
\theta /(1-\theta)=k_{0}\left(P_{H 2}\right)^{0.5},
$$

where $k_{O}$ is a constant and $P_{H 2}$ is the hydrogen partial pressure. If the change in voltage across the hydrogen dipole

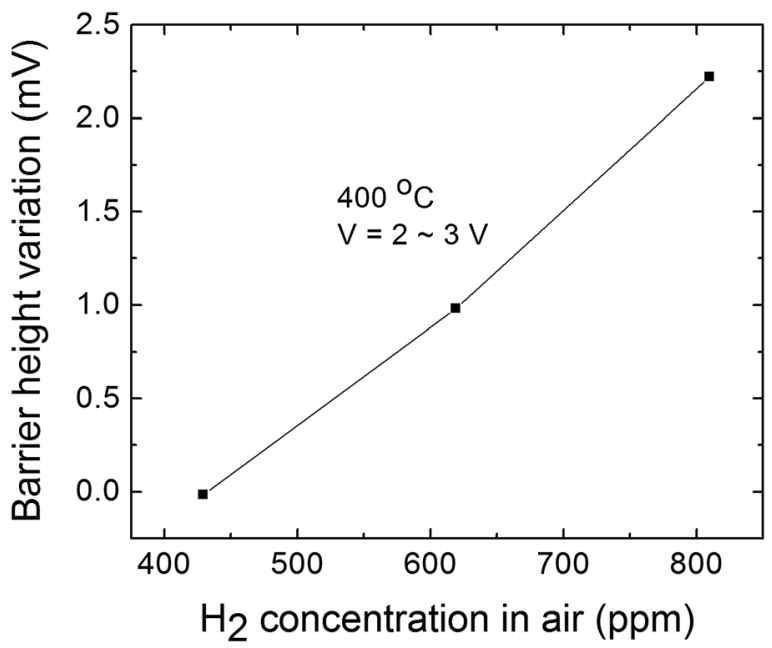

FIG. 7. Barrier-height variation vs $\mathrm{H}_{2}$ concentration characteristics of the sensor. layer $(\Delta V)$ induced by hydrogen adsorption is proportional to the hydrogen coverage, i.e., $\Delta V=\Delta V_{\text {max }} \theta$, then Eq. (2) can be written as

$$
(\Delta V)^{-1}-\left(\Delta V_{\max }\right)^{-1}=\left(\Delta V_{\max }\right)^{-1}\left(k_{0}\right)^{-1}\left(P_{H 2}\right)^{-0.5},
$$

where $\Delta V_{\max }$ is the maximum voltage change at a fixed temperature. After some calculations using Eqs. (3) and (1), we obtain

$$
\left[\ln \left(I_{0 g} / I_{0}\right)\right]^{-1}=\left[\ln \left(I_{0 \text { gmax }} / I_{0}\right)\right]^{-1}\left[1+\left(k_{0}\right)^{-1}\left(P_{H 2}\right)^{-0.5}\right],
$$

where $I_{O}$ and $I_{O g}$ are the saturation current and maximum saturation current in hydrogen environment, respectively. Thus, the plot of $\left[\ln \left(I_{O g} / I_{O}\right)\right]^{-1}$ versus $\left(P_{H 2}\right)^{-0.5}$ should be linear, with the $y$-intercept equal to $\left[\ln \left(I_{O \operatorname{gmax}} / I_{0}\right)\right]^{-1}$ and the slope equal to $\left[k_{0} \ln \left(I_{0 \text { gmax }} / I_{O}\right)\right]^{-1}$. It is shown in Fig. 8 that the plot of $\left[\ln \left(I_{O g} / I_{O}\right)\right]^{-1}$ versus $\left(P_{H 2}\right)^{-0.5}$ for the sensor is indeed linear. Thus, the theory and experimental data via the $I-V$ analysis method confirm the hydrogen reaction kinetics in the sensor. $^{24,25}$

The response time, which is defined as $e^{-1}$ times the final steady-state value, can be obtained from the transientresponse curves shown in Fig. 9. As the temperature increases from 100 to $400{ }^{\circ} \mathrm{C}$, the response time of the sensor is 26.2 and $25.1 \mathrm{~s}$, respectively, which are comparable to others. ${ }^{26}$ The response time generally decreases with increasing operating temperature because higher temperature enables faster hydrogen decomposition and diffusion, and hence faster response. ${ }^{24}$ On the other hand, when temperature increases from 100 to $400{ }^{\circ} \mathrm{C}$, the recovery time is 34.3 and $34.1 \mathrm{~s}$, respectively. In Tsai's paper, ${ }^{27}$ in $9970 \mathrm{ppm}_{2}$, from 327 to $427^{\circ} \mathrm{C}$, the recovery time of the $\mathrm{Pt} / \mathrm{GaN}$ sensor was 10 and $5 \mathrm{~s}$, respectively. Therefore, our recovery time is also comparable to others and is longer than the response time as usual. This hysteresis for hydrogen transport in the

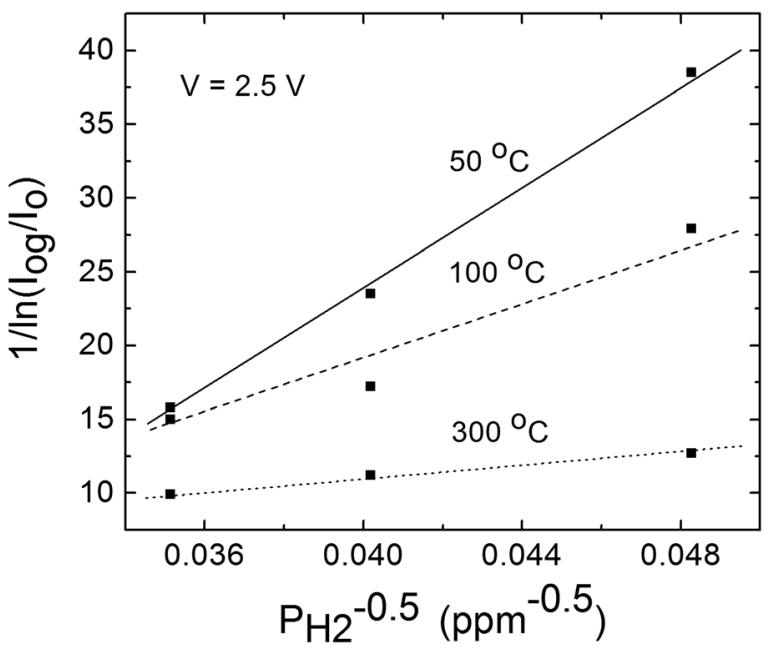

FIG. 8. Steady-state reaction kinetic analysis for hydrogen adsorption of the sensor under forward bias. 


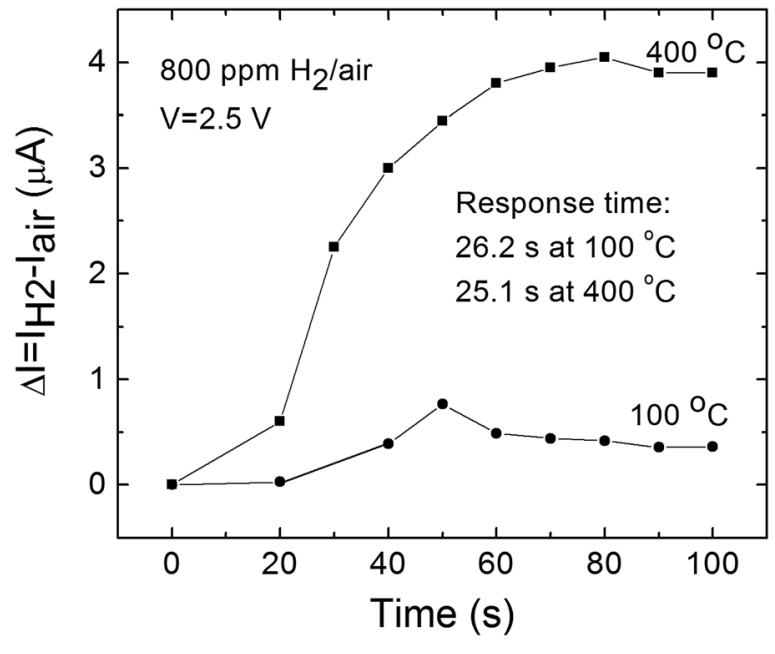

FIG. 9. Hydrogen adsorption transient behavior of the sensor.

metal-hydrogen system is attributed to an energy barrier induced by the lattice misfit between two crystallographic phases, one of which is created by hydrogen absorption. ${ }^{28-30}$ So, the longer recovery time than the response time indicates slower hydrogen desorption, corresponding to slower change back to the original phase.

As depicted in Fig. 10, the hydrogen-adsorption activation energy of the sensor is related to the adsorption rate for hydrogen detection and can be derived by extracting the slope from the Arrhenius plot of current variation rate $(\Delta I / \Delta t)$ versus the inverse of temperature $(1 / T)$. The activation energy is determined based on the highest current variation rate in the first $40 \mathrm{~s}$ (please refer to Fig. 9) upon exposure to $800 \mathrm{ppm}_{2}$ /air for a temperature range from 25 to $400{ }^{\circ} \mathrm{C}$. The resulting Arrhenius plot with error bars yields an activation energy $E_{a}$ of $4.9 \mathrm{kcal} / \mathrm{mol}\left(E_{a}=-\right.$ slope $\times R$ $\times 1000=2.46 \times 8.31 \times 1000=20.4 \mathrm{~kJ} / \mathrm{mol}=4.9 \mathrm{kcal} / \mathrm{mol})$ for the sensor. In other works, the activation energy of a $\mathrm{Pt} / \mathrm{GaN}$ sensor is $7.3 \mathrm{kcal} / \mathrm{mol}$ (Ref. 31) while that of a $\mathrm{Pt} / \mathrm{SiO}_{2} / \mathrm{GaN}$ is $2.9 \mathrm{~kJ} / \mathrm{mol}^{32}$

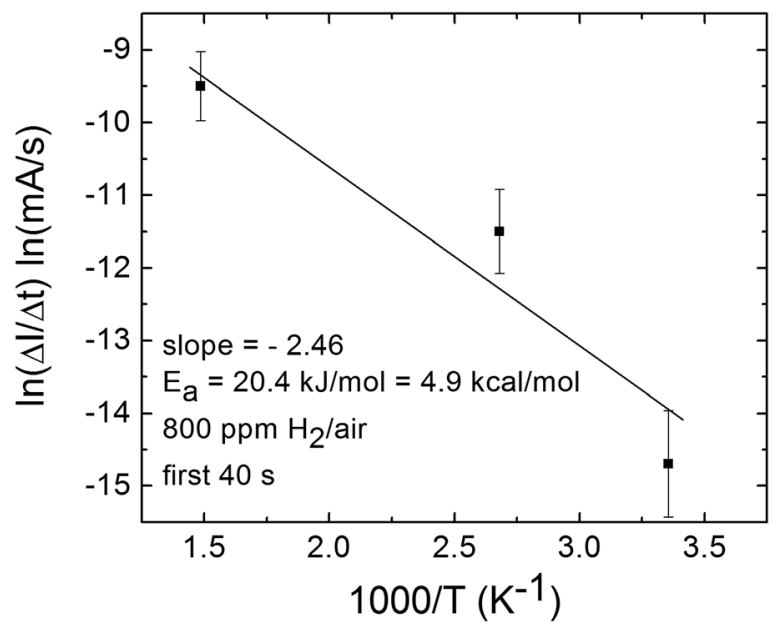

FIG. 10. Arrhenius plot of $\operatorname{In}(\Delta I / \Delta t)$ vs $1 / T$.

\section{CONCLUSION}

InGaN/GaN MQW Schottky-diode hydrogen sensor was made to study its performance in hydrogen detection. It is sensitive to hydrogen ambient even at high temperature (response is 0.11 at $300{ }^{\circ} \mathrm{C}$ in $810 \mathrm{ppm}_{2}$ ), and thus is especially useful for internal combustion engines. Moreover, the hydrogen reaction kinetics is confirmed for the sensor. As the operating temperature increases from 100 to $400{ }^{\circ} \mathrm{C}$, the response time is 26.2 and $25.1 \mathrm{~s}$, respectively. Arrhenius plot yields an activation energy of $4.9 \mathrm{kcal} / \mathrm{mol}$ for the sensor. In summary, the InGaN/GaN MQW Schottky-diode hydrogen sensor has good hydrogen-sensing properties, especially in high-temperature applications.

\section{ACKNOWLEDGMENTS}

This work was financially supported by the Research Grants Council (RGC) of Hong Kong Special Administrative Region (HKSAR), China, under Project CRF (HKUST 2/07C) (Project No. CA07/08.EG02), and the University Development Fund (Nanotechnology Research Institute, 00600009) of the University of Hong Kong.

\footnotetext{
${ }^{1}$ A. Kumar, P. Zhang, A. Vincent, R. McCormack, R. Kalyanaraman, H. J. Cho, and S. Seal, Sens. Actuators B 155, 884 (2011).
}

${ }^{2}$ E.-B. Lee, I.-S. Hwang, J.-H. Cha, H.-J. Lee, W.-B. Lee, J. J. Pak, J.-H. Lee, and B.-K. Ju, Sens. Actuators B 153, 392 (2011).

${ }^{3}$ L. M. Lechuga, A. Calle, D. Golmayo, P. Tejedor, and F. Briones, J. Electrochem. Soc. 138, 159 (1991).

${ }^{4}$ Y.-I. Chou, C.-M. Chen, W.-C. Liu, and H.-I. Chen, IEEE Electron Device Lett. 26, 62 (2005).

${ }^{5}$ B. P. Luther, S. D. Wolter, and S. E. Mohney, Sens. Actuators B 56, 164 (1999).

${ }^{6}$ R. Yatskiv, J. Grym, K. Zdansky, and K. Piksova, 23rd International Conference on Indium Phosphide and Related Materials (Wichmann, Germany, 2011), p. 1.

${ }^{7}$ Y. Xi et al., J. Vac. Sci. Technol. B 31, 032202 (2013).

${ }^{8}$ M. Ali, V. Cimalla, V. Lebedev, H. Romanus, V. Tilak, D. Merfeld, P. Sandvik, and O. Ambacher, Sens. Actuators B 113, 797 (2006).

${ }^{9}$ T.-Y. Chen, H.-I. Chen, P.-S. Chiu, C.-C. Huang, C.-S. Hsu, P.-C. Chou, R.-C. Liu, and W.-C. Liu, Mater. Chem. Phys. 135, 150 (2012).

${ }^{10}$ J. Kim, B. P. Gila, G. Y. Chung, C. R. Abernathy, S. J. Pearton, and F. Ren, Solid-State Electron. 47, 1069 (2003).

${ }^{11}$ S. Suihkonen, O. Svensk, T. Lang, H. Lipsanen, M. A. Odnoblyudov, and V. E. Bougrov, J. Cryst. Growth 298, 740 (2007).

${ }^{12}$ W. Kern, J. Electrochem. Soc. 137, 1887 (1990).

${ }^{13}$ F. Tian, D. Yang, R. L. Opila, and A. V. Teplyakov, Appl. Surf. Sci. 258, 3019 (2012).

${ }^{14}$ Y.-Y. Tsai, S.-Y. Cheng, J.-H. Tsai, D.-F. Guo, H.-I. Chen, and W.-C. Liu, The 14th International Conference on Solid-State Sensors, Actuators and Microsystems (Elsevier, France, 2007), p. 2047.

${ }^{15}$ A. Salehi and V. Nazerian, Conference on Optoelectronic and Microelectronic Materials and Devices (IEEE, Australia, 2006), p. 59.

${ }^{16}$ Xinhua Wang et al., Phys. Status Solidi C 5, 2979 (2008).

${ }^{17}$ J.-R. Huang, W.-C. Hsu, H.-I. Chen, and W.-C. Liu, Sens. Actuators B 123, 1040 (2007).

${ }^{18}$ Y. S. Lin, C. Hsu, K. J. Ma, S. W. Feng, Y. C. Cheng, Y. Y. Chung, C. W. Liu, C. C. Yang, and J. I. Chyi, The 4th Pacific Rim Conference on Lasers and Electro-Optics (IEEE, Japan, 2001), Vol. 2, p. 218.

${ }^{19}$ X. F. Chen, W. G. Zhu, and O. K. Tan, Mater. Sci. Eng. B 77, 177 (2000).

${ }^{20}$ C. F. Lo, C. Y. Chang, B. H. Chu, S. J. Pearton, A. Dabiran, P. P. Chow, and F. Ren, Appl. Phys. Lett. 96, 232106 (2010).

${ }^{21}$ C.-W. Hung, T.-H. Tsai, H.-I. Chen, Y.-Y. Tsai, T.-P. Chen, L.-Y. Chen, K.-Y. Chu, and W.-C. Liu, Sens. Actuators B 128, 574 (2008).

${ }^{22}$ C. Christofides and A. Mandelis, J. Appl. Phys. 68, R1 (1990).

${ }^{23}$ J. Song and W. Lu, IEEE Sens. J. 8, 903 (2008). 
${ }^{24}$ W. M. Tang, "MISiC Schottky-diode hydrogen sensors with different gate insulators," Ph.D. thesis (The University of Hong Kong, 2008).

${ }^{25}$ C. K. Kim, J. H. Lee, Y. H. Lee, N. I. Cho, and D. J. Kim, Sens. Actuators B 66, $116(2000)$.

${ }^{26}$ C.-C. Cheng, Y.-Y. Tsai, K.-W. Lin, H.-I. Chen, C.-T. Lu, and W.-C. Liu, Sens. Actuators B 99, 425 (2004).

${ }^{27}$ T.-H. Tsai, J.-R. Huang, K.-W. Lin, C.-W. Hung, W.-C. Hsu, H.-I. Chen, and W.-C. Liu, Solid-State Lett. 10, J158 (2007).
${ }^{28}$ X. Wei, T. Wei, H. Xiao, and Y. S. Lin, Sens. Actuators B 134, 687 (2008).

${ }^{29}$ Y. Okuhara and M. Takata, Bull. Mater. Sci. 22, 85 (1999).

${ }^{30}$ R. B. Schwarz and A. G. Khachaturyan, Acta Mater. 54, 313 (2006).

${ }^{31}$ J. S. Wright, Wantae Lim, B. P. Gila, S. J. Pearton, and Jason L. Johnson, Sens. Actuators B 140, 196 (2009).

${ }^{32}$ T.-H. Tsai, J.-R. Huang, K.-W. Lin, W.-C. Hsu, H.-I. Chen, and W.-C. Liu, Sens. Actuators B 129, 292 (2008). 